\title{
Fostering EF/SL learners' meta-pragmatic awareness of complaints and their interactive effects
}

\begin{abstract}
This paper suggests a series of steps for teaching complaint behaviour in English. The production of complaints requires a meta-pragmatic awareness of their interactive value and functions, their different types and realisations, pragmalinguistic formulae frequently employed, or the sociopragmatic factors affecting them, among others, which many didactic materials do not address holistically. Integrating relevant findings about complaint behaviour from pragmatics and various neighbouring disciplines, these pedagogical steps combine distinct teaching approaches, include production tasks and guidelines for assessment. Moreover, these steps also comprise an account of some communicative effects of complaints from the cognitive framework of relevance theory with a view to fostering learners' meta-psychological awareness.
\end{abstract}

Keywords: direct/indirect complaints, teaching pragmatics, meta-pragmatic awareness, metapsychological awareness, relevance theory

\section{Introduction}

Complaints are among the speech acts whose accomplishment by learners of English has received attention from practitioners in second language teaching (SLT), interlanguage and intercultural pragmatics (Azarmi \& Behnam, 2012; Boxer, 1993a; Chen et al., 2010; EslamiRasekh, 2004; Kunschak, 2000; Olshtain \& Weinbach, 1993). Syllabi and teaching materials include them at certain proficiency levels but only focus on direct realisations, their value and mitigation, as they are perceived as inherently face threatening (Brown \& Levinson, 1987). Materials neither include information about context and/or interlocutors, which becomes necessary to foresee potential perlocutionary effects, or differentiate indirect complaints. Although these are considered to have a rapport-inspiring function (Boxer, 1993a, 1993b; Boxer \& Pickering, 1995), very few materials discuss how indirect complaints result in rapport and forge common bonds between interlocutors. The nature and contents of explanations about indirect complaints is solely left to teachers, who must rely on their intuition and decide what information to supply. Since SLT aims to foster learners' pragmatic competence (Kasper, 1997), learners should recognise and understand the manifold factors affecting complaint behaviour and determining its effects, as well as how native speakers exploit indirect complaints as a social strategy (Boxer, 1993a; Boxer \& Pickering, 1995). 
Various guidelines for teaching indirect complaints have been suggested to raise learners' awareness of their nature, role, discourse features and the sociocultural factors affecting them. Boxer and Pickering (1995) propose the following teaching stages:

(i) Presenting and discussing indirect complaint sequences from spontaneous speech.

(ii) Presenting samples without their responses and discussing how they make learners feel.

(iii) Eliciting the indirect complaints adequate for given responses.

(iv) Putting in order conversation excerpts containing complaints.

(v) Eliciting learners' estimations about the context - interlocutors' gender, status and distance - where indirect complaints appear, role-playing, videotaping their performance and examining it.

Underscoring that learners must know with whom they could produce indirect complaints, Boxer (2010) suggests other instructional steps centred on the responses likely to create rapport:

(i) Understanding how indirect complaint responses work.

(ii) Recognising speakers' intentions when making indirect complaints.

(iii) Learning to formulate indirect complaints.

(iv) Learning to maintain cohesion and coherence when complaining.

(v) Becoming aware of the effects of interlocutors' identities on the appropriateness of indirect complaints.

These proposals follow others insofar as they include a diagnostic assessment of learners' awareness of the target speech act, use of model dialogues, evaluation of context, feedback and meta-pragmatic discussions (Bardovi-Harlig et al., 1991; Di Pietro, 1987). They purport to endow learners with the background needed to produce indirect complaints in ways that converge with alleged L2 standards and take advantage of the capacity of these acts for 
creating rapport. Nevertheless, if compared to recent works to teach distinct L2 pragmatic areas (Cohen, 2005; Kondo, 2008; Martínez Flor \& Usó Juan, 2006; Padilla Cruz, 2013), these proposals only address quite specific issues about indirect complaints and do not offer a broader framework wherein they can be situated. Efficient pedagogical intervention that can facilitate learners' meta-pragmatic awareness of complaints must rely on a well-structured and research-informed methodological proposal (Ishihara \& Cohen, 2010) which, among other issues, distinguishes direct from indirect complaints, differentiates complaints from other acts, tackles the most relevant features and examines potential outcomes of complaints.

Moreover, Boxer and Pickering (1995) and Boxer's (2010) proposals are mainly concerned with production and overlook comprehension, as they do not address why the effects attributed to indirect complaints arise, i.e., what cognitive processes intervene in their generation. Class discussions with learners of different proficiency levels about audio-visual material in which participants complained about issues such as the weather, local policies, traffic or football unveiled that some learners perceived the individuals who complained as moaners, gripers or whiners (cfr. Márquez-Reiter, 2005). Those learners failed to grasp those participants' intention to establish rapport and solidarity with their interlocutors by touching upon topics about which their interlocutors might have a similar opinion. If it is important for learners to perform speech acts in manners that do not dramatically deviate from L2 patterns, not less important should it be to know the cognitive processes intervening in comprehension with a view to understanding why particular verbal actions may yield specific communicative effects, above all when the effects at stake are as socially significant as the creation of rapport and bonds of union.

This paper presents a proposal for intervention on complaints devised for learners with at least a B1 or pre-intermediate level, for at this level they may be fluent enough, be able to talk about different topics and accomplish various linguistic functions. This proposal seeks to 
overcome the drawbacks of the proposals reviewed above and of available teaching materials. Although it has been applied to different instructional groups, its actual results have not been analysed in depth.

Since complaint behaviour has been examined by pragmatists, ethnographers of speaking and conversation and discourse analysts (see below for references), this proposal incorporates some of their insights in order to achieve a more encompassing intervention. Extant proposals to teach L2 pragmatic aspects agree to scrutinise learners' previous knowledge and/or offering them a general background of the speech act under focus. This includes definition(s), its relation to other speech acts and observation, exploration and contrast between L1 and L2. Next would follow reflecting on the influence of sociocultural factors, discussing potential effects and practice. To conclude, learners should receive feedback about performance, outcomes and possible reactions. This proposal is structured in similar steps.

Additionally, this proposal suggests a way to explain from a cognitive perspective the generation of the effects connected with indirect complaints. In doing so, it applies the pragmatic framework of relevance theory (Sperber \& Wilson, 1995; Wilson \& Sperber, 2004) to SLT, thus showing its usefulness for pedagogical purposes (Jodłowiec, 2010; Maia de Paiva \& Foster-Cohen, 2004) and adding up to existing applications (Ifantidou, 2011; Padilla Cruz, 2010; Tzanne et al., 2009). It assumes that, if learners get acquainted with the reasons why indirect complaints may result in solidarity or rapport, their meta-psychological awareness of the eventual consequences of indirect complaints might achieve a greater sophistication and so the chances that they employ them in order to achieve those effects might increase.

L2 learners' pragmatic abilities have been shown to improve through pedagogic intervention, above all in contexts where they are not directly in contact with the L2 (Kasper \& Rose, 1993; Kasper \& Schmidt, 1996). Although there is inconclusive evidence as to 
whether explicit or implicit teaching is better (Alcón Soler, 2005; Takimoto, 2006) - as speech act knowledge is culturally shared and learners can accomplish diverse speech acts without instruction (Kasper \& Rose, 2001: 5) - awareness-raising activities seem to help them notice frequent features of and strategies to perform L2 speech. Hence, such activities foster learners' L2 meta-pragmatic awareness (Chen et al., 2010; Clennell, 1999; Kasper \& Rose, 2001; Safont Jordá, 2005; Schmidt, 1993) and empower them to render explicit their implicit L2 knowledge, gain insights about its peculiarities, challenge preconceived ideas, become aware of its norms of use or develop some cognitive skills, such as hypothesising or generalising (Tomlinson, 1994). Accordingly, this proposal includes activities like exposure to authentic material, discussions or role-plays.

\section{Defining and identifying complaints}

Instruction could begin by explaining that complaints are acts with which the speaker ${ }^{1}$ (complainer) transmits different negative feelings/attitudes concerning the hearer's (complainee) current or past behaviour, as she feels that his behaviour fails to meet her expectations or violates sociocultural norms. Learners need to know that those feelings/attitudes range from frustration, discomfort, dissatisfaction, discontent or disapproval to extreme anxiety or indignation (Edmondson \& House, 1981; Edwards, 2005; Laforest, 2002). Then, they must be familiarised with the different types of complaints. When the hearer becomes their target, complaints are direct:

(1) You are always so late!

In contrast, if the complainer is angry at another individual's conduct or critically laments events beyond her control or the hearer's, complaints are labelled indirect. It must be clear that these complaints target a third party, since the hearer is not held responsible for any offence. The third party or the event criticised are the complainable (Boxer, 1993a, 1993b; 
Edmondson \& House, 1981; Trosborg, 1995), which is often regarded as some censurable antagonist because of his/its objectionable conduct (Acuña Ferreira, 2002-2003; Günther, 1997):

(2) Peter is so ungrateful! He is always asking for favours he cannot return!

(3) I cannot see the day when these works end!

Attention must also be paid to the similarities and differences with other speech acts. One of the defining properties of complaints is their expressive nature (Searle, 1969), since the complainer expresses a psychological state about a questionable state of affairs. Nonetheless, different taxonomies place complaints under distinct categories. For instance, Edmondson and House (1981) included them within substantive attitudinal illocutions about a non-future event $^{2}$. Regardless of the terminology employed, teachers must underline that the expression of a negative or critical attitude clearly differentiates complaints from other expressive acts like apologies, with which the speaker intends the hearer to know she is sorry for some state that negatively affects him; congratulations, wherein the speaker expresses her pleasure about some state that benefits the hearer and for which he is responsible, or condolences, wherewith the speaker shows that she feels the same as she thinks the hearer does about a negative event affecting him (Edmondson and House, 1981: 51-53). Furthermore, they must stress the retrospective nature of complaints, for the complainer a posteriori judges, criticises or censures a past state of affairs (Edmondson \& House, 1981; Trosborg, 1995):

(4) Yesterday's match was more than disappointing!

(5) You did not put on your suit and tie for yesterday's party!

Apart from an efficient way of escape for indignation, frustration or anger, the complainer could also intend to subtly, and maybe surreptitiously, influence the hearer's behaviour, as in (6), where she might want him to change his pullover:

(6) That pullover is not adequate for the party! 
Learners must know that, in these cases, complaints acquire a prospective nature (MárquezReiter, 2005) and might be pragmatically ambivalent, e.g., between an order and a suggestion. This discharges the speaker from responsibility for performing those acts in case the hearer questioned her position to issue the order or found the suggestion inadequate.

Teachers should also differentiate direct and indirect complaints from the ways in which complaints can be performed: directly or indirectly, depending on whether the complainer's negative evaluation is explicit or implicit (Edmondson \& House, 1981; Trosborg, 1995). Through examples like (7), learners could note that the formula used overtly shows that the complainer accuses the hearer of arriving late and clearly expresses her dissatisfaction with that. In contrast, in (8) the complainee must deduce that the hearer's late arrival, not explicitly mentioned, provokes the speaker's indignation:

(7) You are late!

(8) The lecture has already started!

Teachers might also wish to present other frequent strategies that, though not counting as direct realisations of complaints, somehow enable the hearer to understand speaker meaning, such as presupposing that the hearer is responsible for the offence ('why did you...?'), requesting for repair or change in behaviour ('Next time you...'), or threatening the complainee ('If you are late again, you...') (Chen et al., 2011). Helpful though this may be, teachers should not give the impression that strategies to complain are limited to these, but warn learners that there are not prototypical ones: factors like mood, identity or social relationships determine their selection, variation and possible combinations. Teachers should encourage them to take risks and use diverse formulae, with the caveat that they might be misunderstood and pragmatic failures might arise (Gershenson, 2003; Chen et al., 2011).

Defining and distinguishing complaints can be done adopting an explicit teaching approach, i.e., by means of explanations that direct learners' attention to specific pedagogical 
objectives in a structured way - e.g., following the sequence so far presented - but also adopting an implicit teaching approach, i.e. in a suggestive way by means of adequate input. Through exposure to authentic material containing different types and realisations of complaints, learners could be guided to make relevant deductions by means of awarenessraising questions like these, adapted from Martínez Flor and Usó Juan (2006) and Ishihara and Cohen (2010):

- What is speaker doing when saying utterance $U$ ?

- What is her attitude?

- Why does speaker say $U$ ?

- What or who do you think speaker is criticising, reproaching, etc.?

- What do you think is the speaker's intention?

- What is the difference between $U$ (complaint performed directly) and $Y$ (complaint performed indirectly)?

- $\quad$ Do you think the speaker has some hidden agenda when saying $U$ ?

- Why do you think the speaker said $U$ in this way (indirectly)?

Attention must also be paid to modification of the head act with upgraders or down-toners and to its expansions with moves wherein the complainer justifies the complaint, asks for repair, resolves the matter, makes suggestions, issues orders, negotiates, argues or even socialises with the complainee. These render complaints more natural and sincere (Edwards, 2005; Hartford \& Mahboob, 2004; Murphy \& Neu, 1996; Rubino \& Bettoni, 2006). As the first element of an adjacency pair, direct complaints have no typical second part, since they can be followed by denials or rejections (9), justifications or excuses (10), apologies (11) or other acts (Dersley \& Wooton, 2000; Laforest, 2002; Olshtain \& Weinbach, 1993):

(9) A: Ugh! This wine is heady!

B: Oh, no, it's an excellent wine! 
(10) A: There are so many people here today!

B: Well, today Ricky Martin is signing his new album.

(11) A: Why did you leave all those books over there?

B: Oh, sorry, I thought you wouldn't mind.

Responses to direct complaints are varied, but learners must know that they qualify as evasive strategies, such as minimising the complaint, querying pre-conditions or blaming someone else; apology strategies, like acknowledgement of responsibility and explanations; remedial acts, like offers of repair, showing concern for the complainer or promises of forbearance, and, ultimately, opting out (Trosborg, 1995, 2003; Trosborg \& Shaw, 1998). Responses to indirect complaints include joking/teasing to soften a situation (12); nonsubstantive replies, which show unwillingness to express concern (13); questions, which challenge or lead to elaboration on the complaint (14); advice with moralising purposes (15); contradictions that disagree with the complaint and give rise to subsequent defence (16), or commiseration, which leads to expression of common viewpoints (17) (Boxer, 1993a):

(12) A: But why are these children so untidy!! They leave their toys everywhere!

B: Oh, come on! Don't be such a stick in the mud!

(13) A: I do not know why they built this horrible mall here.

B: Hmn.

(14) A: It's so difficult to find a present for Martha!

B: Do you think she's got one of those woollen scarves?

(15) A: I've been waiting for Susie the whole morning!

B: You should be more patient.

(16) A: People here always come to the same pub!

B: But the music is fabulous!

(17) A: And the teacher has told me to rewrite the whole essay! 


\section{B: That's so unfair!}

As complaints are tackled, many questions may arise about their possible risks and consequences for social interaction. Therefore, teachers should also sensitise learners to issues related to their potential (im)politeness.

\section{Reflecting and reasoning about complaints}

Maybe because of a certain tendency to see verbal actions as detrimental or beneficial for interaction, learners may hesitate about the suitability of complaints. Indeed, complaints have been regarded as conflictive acts (Leech, 1983) which threaten the complainee's positive face, as they suggest that the speaker's wishes do not match the complainee's (Brown \& Levinson, 1987). They are often portrayed as inherently negative (Chen et al., 2011; Edwards, 2005), since upon complaining the speaker 'potentially disputes, challenges, or bluntly denies the social competence of the complainee' (Edmondson \& House, 1981, p. 145).

But complaints may also threaten complainers' positive and negative face, inasmuch as they give the impression that the complainer is a 'whiner' who imposes her troubles on other people (Márquez-Reiter, 2005). Learners should know that these risks pertain to direct complaints targeted to the hearer; those of indirect complaints may stem from the 'talkability' of their topics, which depends on cultural norms (Sell, 1991), the set of rights interlocutors grant to each other, their respective social obligations or their quality and identity face (Spencer-Oatey, 2008). Furthermore, indirect complaints may work as efficient mechanisms of association between interlocutors resulting in emotional reciprocity, rapport, strengthening of bonds of solidarity, reaffirmation of complicity or the construction of a common identity.

Therefore, they could function as face boosting acts (Boxer, 1993a, 1993b, 2010; Boxer \& Pickering, 1995; Drew, 1998; Günthner, 1997).

Adopting a pragmatic perspective, teachers can explain that these complaints contribute to 
those feelings for two reasons. On the one hand, like phatic communion, they may be motivated by the complainer's abidance by interactive norms that encourage her to avoid silence in situations in which absence of conversation could be uneasy. By venting her indignation, the complainer would 'break the ice' and introduce a topic for subsequent conversation (Leech, 1983; Schneider, 1988). On the other hand, indirect complaints somehow presuppose common ground or suggest affinity with the complainee as regards viewpoints, preferences, wishes and attitudes to the complainable (Boxer 1993a). In fact, indirect complaints have been considered positive-politeness strategies that behave as some sort of social accelerator by implicitly indicating common membership in a group with a particular opinion about and attitude to the complainable (Brown \& Levinson, 1987).

Teachers could also illustrate the conversational devices used to invite affiliative display in indirect complaint sequences by indicating that complainers may resort to:

- hilarious or dramatic narrations, which show that complaints should not be taken as serious attacks,

- reported speech and parody that sets impressive and/or exaggerated contrasts with appropriate events or conducts,

- staging of the events or conducts constituting the topic of complaints, and/or

- laughter, interjections, prosody, gestures and facial expressions.

When dealing with these, teachers can also point out remarkable gender and cross-cultural differences (Acuña-Ferreira, 2002-2003; Boxer, 1993a; Chen et al., 2011; Edwards, 2005; Eslami-Rasekh, 2004; Günthner, 1997; Olshtain \& Weinbach, 1993).

Nevertheless, learners must be alerted that indirect complaints do not always function as positive-politeness strategies. The speaker's intentions, the politeness system in which interlocutors interact (Scollon \& Wong-Scollon, 1995), their rights and obligations (SpencerOatey, 2008), or the way in which the hearer might interpret them may achieve a great 
importance. For instance, an indirect complaint about the weather, like (18), may be a positive-politeness strategy in a solidarity politeness system where interlocutors are close friends, there is no power-difference and the complainer knows that the complainee does not like rainy days:

(18) When will this damned rain stop?

In contrast, this complaint may act as a negative-politeness strategy in a deference politeness system $^{3}$ where interlocutors do not know each other, if the complainer avoids another more 'personal' or controversial topic.

Although this sort of explanation may increase learners' meta-pragmatic awareness of the interactive effects of indirect complaints, instructors should avoid generalisations based on observations of regularities in verbal behaviour and consider complementary ones. These should delve into utterance production and comprehension (Sperber \& Wilson, 1997) and solve problems like:

a) When can indirect complaints result in solidarity or affinity?

b) Which cognitive processes might take place in the interlocutors' mind when producing and interpreting them?

The next section describes how teachers can explain why indirect complaints contribute to solidarity. Since this proposal relies on the cognitive perspective on communication offered by relevance theory (Sperber \& Wilson, 1995; Wilson and Sperber, 2004), a brief explanation of some of its key concepts and its portrait of understanding is given first.

\section{Explaining the generation of rapport}

\section{Relevance and understanding}

Relevance theory (Sperber \& Wilson, 1995; Wilson \& Sperber, 2004) assumes that individuals create mental representations of perceived facts, events or objects, which become 
manifest - i.e. mentally represented. The representations, assumptions or thoughts stored in our minds makes up our cognitive environment. Cognitive environments may intersect with those of other individuals if similar facts or assumptions are manifest to them. However, people never share their total cognitive environments because their physical environments are never identical and their cognitive abilities may be affected by mental states and previously stored information (Sperber \& Wilson, 1995, pp. 41-45).

Relevance theory also claims that communication is an ostensive-inferential activity in which speakers intentionally draw hearers' attention by means of utterances. These are public representations of other private representations - the speaker's thoughts - so they are metarepresentations of those representations. Through utterances, speakers make manifest a set of assumptions that constitute their informative intention. But humans can also attribute thoughts and/or intentions to other individuals, i.e. 'read' their minds, and make attributive metarepresentations (Wilson, 1999). For hearers to metarepresent the thoughts that speakers intend to communicate, it is essential that they recognise an intention to communicate them: their communicative intention.

Upon recognising that intention, communication proceeds as follows (Sperber \& Wilson, 1995; Wilson \& Sperber, 2004). Hearers decode utterances and obtain a logical form - a structured set of concepts - which is not fully propositional, as it is non-truth-evaluable. Then, they inferentially enrich that form with contextual information and construct the lower-level explicature of the utterance. During enrichment, the hearer must also infer the speaker's attitude towards the propositional content communicated and embed the lower-level explicature of the utterance under a speech-act or propositional-attitude description. The result of this process is the higher-level explicature of the utterance. Additionally, the hearer may relate the information the utterance makes manifest to other information he thinks the speaker intends him to use - i.e. implicated premises. Thus, he can reach the implicated conclusions 
that the speaker might expect.

\section{On the generation of rapport}

In order to account for the generation of rapport, teachers may consider two situations. In the first interlocutors would not know each other beforehand, so they are not certain about what the other thinks about specific facts. Nevertheless, this does not exclude that they share some cultural knowledge if they belong to the same cultural group. Indirect complaints would achieve those effects if there were a fortuitous intersection of the interlocutors' cognitive environments, i.e., if the same facts were manifest to them.

Through an indirect complaint the speaker makes manifest assumptions that may resemble those manifest to the hearer. Even if both individuals had similar cognitive abilities, these may be attuned differently and conditioned by memorised information, so they may perceive differently and their cognitive environments may vary (Sperber \& Wilson, 1995, pp. 41-45). However, the complaint may cause the hearer to think about the thoughts that the speaker entertains. The hearer may thus sense that the thoughts manifest to himself and other assumptions he can derive from them may be similar to (a) the speaker's thoughts and (b) other assumptions the speaker can derive. Such similarity will increase if the hearer feels that both of them could derive further similar assumptions from the complaint and the thoughts it triggers.

With indirect complaints the speaker also expresses an attitude to the complainable, which may induce the hearer to have a similar one to it and sense that his attitude is the same as, or fairly similar to, the speaker's. Accordingly, in this situation indirect complaints may result in rapport if the complainee can attribute to the complainer thoughts that are similar to his, the possibility of drawing from them conclusions similar to the ones he can derive and an attitude similar to his. 
To understand this, learners could consider examples like (19), an indirect complaint in a cognitive environment in which it is manifest to interlocutors that it is taking more than expected to finish the underground in their city:

(19) This is unbelievable! Now they give a new date for the opening of the underground! I don't know when they are going to finish it!

Learners should notice that, when processing complaints like (19), the complainee will have to enrich their logical forms in order to construct their explicatures (Sperber \& Wilson, 1995, p. 78). The complainee must determine, among others, whom the complainer refers to with 'they', which underground is alluded to, why the date for its opening is a new one, if the complainer is surprised, frustrated or annoyed and to what extent. Upon constructing the explicature, if the complainee senses that it corresponds to what the interlocutor thinks and communicates with that utterance, he could feel that the assumptions manifest to himself may be similar to what the complainer thinks.

Learners must also bear in mind that, for the interlocutors' respective thoughts to be similar, each of them should feel that the other individual may also derive implications from them. For instance, (19) can contextually imply (20):

(20) a. The construction of the new underground is taking more than expected.

b. Traffic conditions will continue to be chaotic.

If both interlocutors derive implications like these, the similarity between the thoughts that the complainer metarepresents through the complaint and those the complainee entertains will increase, and so will the feeling of rapport or affinity between them. Finally, learners must pay attention to the fact that those effects depend on the complainee's awareness of the complainer's surprise, frustration or annoyance at the states of affairs mentioned and on their experiencing similar feelings.

In the second situation, interlocutors know each other to some extent, so the intersection 
of their cognitive environments may be intentionally caused by the speaker, who knows what the complainee is likely to think about the complainable and the attitude(s) he may have. Since indirect complaints may be targeted at complainables with which both interlocutors are acquainted, such complaints would be phatic and increase the manifestness of assumptions already manifest (Žegarac \& Clark, 1999). The complainer can exploit this in order to achieve feelings of affinity: by means of an indirect complaint she may attribute to the complainee the manifestness of assumptions similar to the ones manifest to herself or, in other words, she may show her awareness that the complainee also entertains similar thoughts about the complainable. Therefore, indirect complaints behave as attributive metarepresentations.

To illustrate this, students could consider the indirect complaint (21) in a mutual cognitive environment in which interlocutors already know that the tram in their city is too noisy:

(21) This damned tram is so noisy!

Teachers could explain that the complainer metarepresents not only her thoughts, but also thoughts which she thinks, or has evidence to think, are similar to those of the complainee's. When processing the complaint, the complainee will realise that such similarity actually arises if he feels that the outcome of the pragmatic enrichment of its logical form - i.e. reference assignment to 'tram', determination of degree of noisiness (Sperber \& Wilson, 1995, p. 78) matches what the complainer intends to communicate and that what he then thinks and the implications that he can derive from it may be similar to what the complainer thinks and to the implications that she may derive. In other words, teachers can tell learners that, if (21) makes the complainee derive implications like those in (22) and he feels that the complainer can also do so, the complainee will believe that they have very similar viewpoints and therefore experience rapport:

(22) a. The city council will have to do something to solve this problem.

b. The city council may expect complaints from neighbours along the tram-line. 
Complainers express a range of attitudes to the complainable which might be similar, if not identical, to that/those of the complainee's. The higher-level explicature that the complainee constructs will refer to it/them:

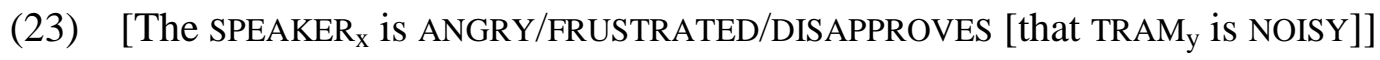
Teachers may comment that the complainer's attitude(s) may count as endorsement with the attitude(s) she takes the complainee to have: with it/them the complainer shows that her own attitude(s) resemble(s) the one(s) that the complainee has to the complainable. This may lead the complainee to reach implicatures concerning the fact that the complainer shares the same attitude(s) and endorses his. Such endorsement will blend with the primary attitude of frustration, dissatisfaction, discontent, etc. the complainer expresses and yield a combination of attitudes that could be labelled rejecting agreement, disapproving agreement, or agreement in frustration/dissatisfaction/indignation/disapproval/etc., depending on the prevalent attitude of complainer's (Padilla Cruz, 2012). Accordingly, teachers could stress that rapport in this situation arises if

(i) the complainer metarepresents thoughts that are similar to those of the complainee's and expresses (an) attitude(s) to the complainable similar to that/those of the complainee, and

(ii) the complainee is aware that both of them entertain similar thoughts and the complainer endorses his negative attitude to the complainable.

Such endorsement is essential for seeking or intensifying rapport and affinity, as it indicates that the complainer notices and/or approves of the complainee's interests, concerns or worries; suggests that both individuals belong to a group that has an opinion about and/or reaction to something, and presupposes or raises common ground.

\section{Wrapping instruction up}


To conclude, learners should practice through diverse tasks that check their awareness of pragmalinguistic resources to complain, sociopragmatic factors affecting complaints (Martínez Flor \& Usó Juan, 2006) and the reasons why rapport may arise. In addition to the activities suggested by Boxer and Pickering (1995) and Boxer (2010), controlled oral activities that could work well are:

- Role-plays in contexts matching different politeness systems, so that learners decide whether to complain or not, and the best complaint strategy.

- Presenting censurable facts so that learners predict what their interlocutors might think about them and the thoughts they could trigger. Learners would then supply complaints that show that they think in a similar way to their interlocutors.

- Presenting situations without obvious censurable facts so that learners select complainables and formulate different complaints on the basis of their awareness of their interlocutors potentially having a viewpoint similar to theirs.

- Videos showing offences, misbehaviours or trespasses, which are paused when the ensuing complaints are about to appear. Learners answer questions or fill in a questionnaire about the interactive context, the interlocutors' relationship, non-verbal behaviour, the thoughts they may entertain or the type of complaint they would expect. Next, they would show how they think the conversation would continue and they watch how the interlocutors in the video actually behave.

Controlled written activities could include:

- Contextualised gapped sentences that call for specific complaints depending on sociopragmatic factors.

- Discourse Completion Tests eliciting complaints and/or responses to them in various situations ${ }^{4}$.

- Descriptions of thoughts and contextual assumptions that an individual may entertain 
and which would be manifest to a complainer. Learners would have to supply complaints that suggest endorsement with the complainee.

- Analysis of documents containing complaints (letters, emails, etc.).

Free oral activities could rely on synchronous computer-mediated communication (CMC), particularly video-conferencing programs. These enable learners to reflect on how they complain or respond to complaints and their responses and overcome the difficulties of collecting data of learners' complaint behaviour in non-elicited situations (Martínez Flor \& Usó Juan, 2006). In contrast, asynchronous CMC could be exploited for free written tasks, such as postings, blogs, emails or conversations in chat-rooms or forums. These have advantages such as organising messages thematically or creating databases of samples (Ishihara, 2010a) ${ }^{5}$.

Upon revising the outcomes of tasks, teachers' feedback should focus on performance and take into account pragmalinguistic issues like the extent to which learners understand other people's utterances as complaints or their own utterances are likely to be understood as such. Feedback should also address sociopragmatic issues like the extent to which learners perceive and understand the influence of sociocultural factors on complaint behaviour and its consequences. Accordingly, teachers could comment on the vocabulary, strategies and formulae that learners resort to, as well as on their level of directness, adherence to L2 norms or paralanguage (Ishihara, 2010b). Finally, teachers could check if indirect complaints make learners experience rapport and why (not).

\section{Conclusion}

In addition to developing learners' meta-pragmatic awareness of the characteristics, realisations and risks of L2 verbal acts, instruction must also develop their metapsychological awareness of the effects they may bring about with those acts. This paper has 
suggested a methodological proposal for complaints based on contributions from different disciplines. It rests on explicit and implicit teaching and includes diverse tasks centred on pragmalinguistic and sociopragmatic issues, which enable learners to practice and realise further or recurrent deficits. It also includes some guidelines to assess learners' performance and awareness of pragmatic aspects and provide them with helpful feedback. A more complete proposal should consider types of learners, disparity in proficiency levels or class dynamics.

This proposal relies on the relevance-theoretic framework in order to describe why indirect complaints may generate rapport. Readers might question the plausibility of a proposal resting on hypothetical mental states and processes. Although cognitive models offer stipulated reconstructions of what happens in the human mind when processing discourse, their empirical basis enable them to offer valuable insights into mental workings. These may inform illustrations of the generation of some communicative effects like the one suggested here.

\section{Notes}

1. Reference to the speaker and hearer is made through the third person singular feminine and masculine pronouns, respectively.

2. Edmondson and House (1981) differentiate ritual and substantive illocutions, wherewith speakers attempt to achieve some conversational outcome.

3. Solidarity systems are characterised by low distance and no power-difference, whilst deference ones by high distance, regardless of status-differences (Scollon \& WongScollon, 1995).

4. For a discussion about their (dis)advantages, see Garcés-Conejos Blitvich (2006) and Cohen (2006). 
5. See Padilla Cruz (2013) for details about these activities.

\section{References}

Acuña Ferreira, V. (2002-2003). Gendered emotive displays in complaint discourse. Estudios de Sociolingüística, 3-4, 139-172.

Alcón Soler, E. (2005). Does instruction work for learning pragmatics in the EFL context? System, 33, 417-435.

Azarmi, A., \& Behnam, B. (2012). The pragmatic knowledge of Iranian EFL learners in using face keeping strategies in reaction to complaints at two different levels. English Language Teaching, 5, 78-92.

Bardovi-Harlig, K, Hartford, B. A. S., Mahan-Taylor, R., Morgan, M. J., \& Reynolds, D. W. (1991). Developing pragmatic awareness: closing the conversation. ELT Journal, 45, 4-15.

Boxer, D. (1993a). Complaints as positive strategies: What the learner needs to know. TESOL Quarterly, 27, 277-299.

Boxer, D. (1993b). Social distance and speech behaviour: The case of indirect complaints. Journal of Pragmatics, 19, 103-105.

Boxer, D. (2010). Complaint: How to gripe and establish rapport. In A. Martínez Flor and E. Usó Juan (Eds.), Speech act performance. Theoretical, empirical and methodological issues (pp. 163-178). Amsterdam: John Benjamins.

Boxer, D., \& Pickering, L. (1995). Problems in the presentation of speech acts in ELT materials: The case of complaints. ELT Journal, 49, 44-58.

Brown, P., \& Levinson, S. C. (1987). Politeness. Some universals in language usage. Cambridge: Cambridge University Press. 
Chen, Y. S., Chen, C. Y., \& Chang, M. H. (2010). The effects of instruction on Chinese university students' production of complaint behaviour in American English. Taiwan Journal of TESOL, 7, 29-65.

Chen, Y. S., Chen, C. Y., \& Chang, M. H. (2011). American and Chinese complaints: Strategy use from a cross-cultural perspective. Intercultural Pragmatics, 8, 253-275.

Clennell, C. (1999). Promoting pragmatic awareness and spoken discourse skills with EAP classes. ELT Journal, 53, 83-91.

Cohen, A. D. (2005). Strategies for learning and performing L2 speech acts. Intercultural Pragmatics, 2, 275-301.

Cohen, A. D. (2006). Interlanguage pragmatics: A reply to Pilar Garcés-Conejos Blitvich. Intercultural Pragmatics, 3, 359-364.

Dersley, I., \& Wootton, A. (2000). Complaint sequences within antagonistic argument. Research on Language and Social Interaction, 33, 375-406.

Di Pietro, R. J. (1987). Strategic interaction. London: Cambridge University Press.

Drew, P. (1998). Complaints about transgressions and misconduct. Research on Language and Social Interaction, 31, 295-325.

Edmondson, W., \& House, J. (1981). Let's talk and talk about it. München: Urban \& Schwarzenberg.

Edwards, D. (2005). Moaning, whinging and laughing: The subjective side of complaints. Discourse Studies, 7, 5-29.

Eslami-Rasekh, Z. (2004). Face-keeping strategies in reaction to complaints. English and Persian. Journal of Asian Pacific Communication, 14, 181-197.

Garcés-Conejos Blitvich, P. (2006). Interlanguage pragmatics: A response to Andrew Cohen's "Strategies for learning and performing L2 speech acts" published in Vol. 2, No. 3, of Intercultural Pragmatics. Intercultural Pragmatics, 3, 213-223. 
Gershenson, O. (2003). Misunderstanding between Israelis and Soviet immigrants: Linguistic and cultural factors. Multilingua, 22, 275-290.

Günthner, S. (1997). Complaint stories. Constructing emotional reciprocity among women. In H. Kotthoff \& R. Wodak (Eds.), Communicating gender in context (pp. 179-218). Amsterdam: John Benjamins.

Hartford, B., \& Mahboob, A. (2004). Models of discourse in letter of complaint. World Englishes, 23, 585-600.

Ifantidou, E. (2011). Genres and pragmatic competence. Journal of Pragmatics, 43, 327-346.

Ishihara, N. (2010a). Incorporating technology into pragmatics-focused instruction. In N. Ishihara \& A. D. Cohen, Teaching and learning pragmatics. Where language and culture meet (pp. 244-263). Harlow: Pearson.

Ishihara, N. (2010b). Assessment of pragmatics in the classroom. In N. Ishihara \& A. D. Cohen, Teaching and learning pragmatics. Where language and culture meet (pp. 286-317). Harlow: Pearson.

Ishihara, N., \& Cohen, A. D. (2010). Teaching and learning pragmatics. Where language and culture meet. Harlow: Pearson.

Jodłowiec, M. (2010). The role of relevance theory in SLA studies. In M. Pütz \& L. Sicola (Eds.), Cognitive processing in second language acquisition (pp. 49-66). Amsterdam: John Benjamins.

Kasper, Gabriele. (1997). Can pragmatic competence be taught? (NetWork \#6). Honolulu: University of Hawai'i, Second Language Teaching \& Curriculum Center. Retrieved from http://www.nflrc.hawaii.edu/NetWorks/NW06/

Kasper, G., \& Rose, K. R. (Eds.) (1993). Pragmatics in language teaching. Cambridge: Cambridge University Press.

Kasper, G., \& Rose, K. R. (2001). Pragmatics in Language Teaching. In K. R. Rose \& G. 
Kasper (Eds.), Pragmatics in Language Teaching (pp. 1-9). Cambridge: Cambridge University Press.

Kasper, G., \& Schmidt, R. (1996). Developmental issues in interlanguage pragmatics. Studies in Second Language Acquisition, 18, 149-169.

Kondo, S. (2008). Effects of pragmatic development through awareness-raising instruction: Refusals by Japanese EFL learners. In E. Alcón Soler \& A. Martínez Flor (Eds.), Investigating pragmatics in foreign language learning (pp. 153-177). Bristol: Multilingual Matters.

Kunschak, C. (2000). Complaint strategies in Viennese German as presented in authentic texts for listening comprehension. MIT Working Papers in Linguistics, 38, 143-157.

Laforest, M. (2002). Scenes of family life: Complaining in everyday conversation. Journal of Pragmatics, 34, 1595-1620.

Leech, G. (1983). Principles of pragmatics. London: Longman.

Maia de Paiva, B. M., \& Foster-Cohen, S. H. (2004). Exploring the relationships between theories of second language acquisition and Relevance Theory. Second Language Learning, 20, 281-288.

Márquez-Reiter, R. (2005). Complaint calls to a caregiver service company: The case of desahogo. Intercultural Pragmatics, 2, 481-514.

Martínez Flor, A., \& Fukuya, Y. J. (2005). The effects of instruction on learners' production of appropriate and accurate suggestions. System, 33, 463-480.

Martínez Flor, A., \& Usó Juan, E. (2006). A comprehensive pedagogical framework to develop pragmatics in the foreign language classroom: The 6Rs approach. Applied Language Learning, 16, 39-64.

Murphy, B., \& Neu, J. (1996). My grade's too low: The speech act set of complaining. In S. M. Gass \& J. Neu (Eds.), Speech acts across cultures: Challenges to communication in 
second language (pp. 191-216). Berlin: Mouton de Gruyter.

Olshtain, E., \& Weinbach, L. (1993). Interlanguage features of the speech act of complaining.

In S. Blum-Kulka \& G. Kasper (Eds.), Interlanguage pragmatics (pp. 108-122). Oxford: Oxford University Press.

Padilla Cruz, M. (2010). Teaching interjections in the ESL/EFL class: A pragmatic approach. In L. Pérez Ruiz, I. Parrado Román \& P. Tabarés Pérez (Eds.), Estudios de metodología de la lengua inglesa, vol. V (pp. 23-33). Valladolid: Universidad de Valladolid.

Padilla Cruz, M. (2012). Metarepresentation, attitudinal utterances and attitude combination: A relevance-theoretic approach. In A. Piskorska (Ed.), Relevance studies in Poland. Volume 4: Essays on language and communication (pp. 75-88). Warsaw: Wydawnictwa Uniwersytetu Warszawskiego.

Padilla Cruz, M. (2013). An integrative proposal to teach the pragmatics of phatic communion in ESL classes. Intercultural Pragmatics, 10, 131-160.

Rubino, A., \& Bettoni, C. (2006). Handling complaints cross-culturally: Italians vs. AngloAustralians. Studi Italiani di Linguistica Teorica e Applicata, 35, 339-358.

Safont Jordá, M. P. (2005). Third language learners. Pragmatic production and awareness. Clevedon: Multilingual Matters.

Schmidt, R. (1993). Consciousness, learning and interlanguage pragmatics. In G. Kasper \& S. Blum-Kulka (Eds.), Interlanguage pragmatics (pp. 21-42). Oxford: Oxford University Press. Schneider, K. P. (1988). Small talk. Analysing phatic discourse. Marburg: Hitzeroth.

Scollon, R., \& Wong-Scollon, S. (1995). Intercultural communication. A discourse approach. Cambridge: Blackwell.

Searle, J. R. (1969). Speech acts. An essay on the philosophy of language. Cambridge: Cambridge University Press. 
Sell, R. D. (1991). The politeness of literary texts. In R. D. Sell (Ed.), Literary pragmatics (pp. 208-224). London: Routledge.

Spencer-Oatey, H. (Ed.) (2008). Culturally speaking. Culture, communication and politeness. London: Continuum.

Sperber, D., \& Wilson, D. (1995). Relevance. Communication and cognition (2 ${ }^{\text {nd }}$ ed.). Oxford: Blackwell.

Sperber, D., \& Wilson, D. (1997). Remarks on relevance theory and the social sciences. Multilingua, 16, 145-151.

Takimoto, M. (2006). The effects of explicit feedback on the development of pragmatic proficiency. Language Teaching Research, 10, 393-417.

Tomlinson, B. (1994). Pragmatic awareness activities. Language Awareness, 3, 119-124.

Trosborg, A. (1995). Interlanguage pragmatics. Requests, complaints and apologies. Berlin: Mouton de Gruyter.

Trosborg, A. (2003). The teaching of business English. In A. Martínez Flor, E. Usó Juan \& A. Fernández Guerra (Eds.), Pragmatic competence and foreign language teaching (pp. 247281). Castellón de la Plana: Publicacions de la Universitat Jaume I.

Trosborg, A., \& Shaw, P. (1998). "Sorry does not pay my bills". The handling of complaints in everyday interaction/cross-cultural business interaction. Hermes, Journal of Linguistics, 21, 67-94.

Tzanne, A., Ifantidou, E, \& Mitsikopoulou, B. (2009). Raising and assessing pragmatic awareness in L2 academic language learning. The International Journal of Learning, 16, 297309.

Wilson, D. (1999). Metarepresentation in linguistic communication. UCL Working Papers in Linguistics, 11, 127-161.

Wilson, D., \& Sperber, D. (2004). Relevance theory. In L. Horn \& G. Ward (Eds.), The 
handbook of pragmatics (pp. 607-632). Oxford: Blackwell.

Žegarac, V., \& Clark, B. (1999). Phatic interpretations and phatic communication. Journal of Linguistics, 35, 321-346. 